\title{
More Resilience in Males with Probable Bipolar Depression than Probable Unipolar Depression among Korean Conscripts
}

\author{
Ji-Yeong Seo ${ }^{1}$, Dawon Lee ${ }^{2}$, Dongyun Lee ${ }^{\otimes}$, Boseok Cha ${ }^{3,4}$, Chul-Soo Park ${ }^{3,4}$, \\ Bong-Jo Kim ${ }^{3,4}$, Cheol-Soon Lee ${ }^{1,4}$, So-Jin Lee ${ }^{3,4}$, In-Young Ahn', and Jae-Won Choi ${ }^{5}$ \\ ${ }^{1}$ Department of Psychiatry, Gyeongsang National University Changwon Hospital, Changwon, Republic of Korea \\ 2Department of Psychiatry, the Armed Forces Capital Hospital, Seongnam, Republic of Korea \\ ${ }^{3}$ Department of Psychiatry, Gyeongsang National University Hospital, Jinju, Republic of Korea \\ ${ }^{4}$ Department of Psychiatry, Gyeongsang National University College of Medicine, Jinju, Republic of Korea \\ ${ }^{5}$ Department of Psychiatry, Seoul National University Hospital, Seoul, Republic of Korea
}

Objective This study investigated whether the resilience of males with probable bipolar depression (PBD) can be strengthened and compared it to that of males with probable unipolar depression (PUD).

Methods Prospective data for 198 participants (PBD: 66, PUD: 66, normal control: 66) were analyzed. The participants' resilience, bipolarity and severity of depressive symptoms were evaluated at baseline and after 5 weeks. Analysis of variance (ANOVA) and repeated measure ANOVA was performed for comparing resilience between three groups through a basic military training.

Results The PBD group demonstrated more resilience than the PUD group at baseline. Participants with PBD became significantly more resilient than participants with PUD after 5 weeks $\left(\mathrm{p}<0.01, \mathrm{~F}=6.967, \eta^{2}{ }_{p}=0.052\right)$.

Conclusion The study indicates that interventions that strengthen resilience need to be developed for males with PBD and that such interventions are more effective for males with PBD than PUD.

Psychiatry Investig 2017;14(5):603-608

Key Words Probable bipolar depression, Probable unipolar depression, Resilience.

\section{INTRODUCTION}

Resilience has been defined as an individual's ability to more effectively cope with stress and adapt in the face of adversity or trauma than other individuals. ${ }^{1}$ Recently, the concept of resilience has been used worldwide and in various fields, from mental health to social sciences, because of unexpected terror attacks and frequent nature disasters. ${ }^{2,3}$ Interestingly, resilience can be promoted through psychiatric intervention.,

Over the past several years, training programs aimed at promoting resilience have been developed. A recent study on the US army suggested that such programs could improve resilience. ${ }^{6}$ Furthermore, recent studies found that a resilience pro-

Received: February 12, 2017 Revised: March 22, 2017

Accepted: April 24, 2017 Available online: June 16, 2017

$\triangle$ Correspondence: Dongyun Lee, MD

Department of Psychiatry, Gyeongsang National University Changwon Hospital, 11 Samjeongja-ro, Seongsan-gu, Changwon 51472, Republic of Korea Tel: +82-55-214-3801, Fax: +82-55-214-3254, E-mail: yuny0829@gmail.com

(c) This is an Open Access article distributed under the terms of the Creative Commons Attribution Non-Commercial License (http://creativecommons.org/licenses/bync/4.0) which permits unrestricted non-commercial use, distribution, and reproduction in any medium, provided the original work is properly cited. gram for the prevention and treatment of depression was effective in reducing depressive symptoms and protecting individuals against adversities. ${ }^{78}$ And, a previous study showed that the resilience of non-clinical samples with mental disorders could be strengthened through intervention. ${ }^{9}$ Strengthening resilience is an important care strategy for patients with bipolar disorder because resilience is a protective factor against the recurrence of mood episodes among these patients. ${ }^{10}$ However, whether interventions that strengthen the resilience of people with bipolar disorder and unipolar depression differ is unknown.

In several countries, young healthy males are required to serve in the military, typically beginning in late adolescence to early adulthood. Conscripts could experience reduced stress levels, as a positive psychological reward, after successfully completing basic military training. ${ }^{11}$ Furthermore, according to previous study of the US military and a recent meta-analysis study, physical fitness and religious activities could have a positive impact on resilience. ${ }^{12,13}$ Therefore, the basic military training that Korean conscripts have experienced, such as regular physical fitness training reflecting their physical con- 
dition and religious activities, could cause improvements in resilience.

Previous studies have not sufficiently explained how resilience can be altered. Especially, it is not known whether the alternation of resilience is different among people with other mood disorders. Previous studies suggested the positive aspects of individuals with bipolar disorder, such as positive response in life stress, and lower risk for posttraumatic stress disorder (PTSD) in patients with history which had overcome the PTSD than in patients without a history of PTSD. ${ }^{14-16}$ Therefore, we hypothesized males with probable bipolar depression (PBD) would be more resilient than probable unipolar depression (PUD).

The aim of this study was to investigate whether the resilience of males with probable bipolar depression (PBD) can be strengthened and to compare it with that of males with probable unipolar depression throughout basic military training after controlling for depressive symptoms.

\section{METHODS}

\section{Subjects and procedure}

This study examined Korean conscripts admitted to a basic military training camp in 2015. The absence of marked medical and psychiatric diseases among subjects was confirmed through the national draft examination. Conscripts were informed of the survey and methods and signed written consent forms before beginning their training. Basic military training in Korea consists of the content, including regular basic physical training, mental training, religious activities, military manners and basic military skills training, for 5 weeks. This study was prospectively designed, and the survey was administered before the start of basic training and repeated 5 weeks later. At baseline, participants completed self-report questionnaires, including a survey of socio-demographic characteristics, the Connors-Davidson Resilience Scale (CDRISC), the Korean version of Mood Disorder Questionnaire (K-MDQ), the Center for Epidemiological Studies-Depression Scale (CES-D), and the Barratt Impulsiveness Scale-11-Revised (BIS-11-R). After 5 weeks, participants completed self-report questionnaires, including the CDRISC and CES-D. A total of 227 subjects participated in this study, and the data of 198 participants were analyzed. This study was approved by the Clinical Medical Research Ethics Committee of the Korean Armed Forces Medical Command.

\section{Measurements}

\section{Resilience}

The CDRISC is a measure used to assess resilience. Connor and Davidson developed the scale, which consists of 25 items, in 2003. ${ }^{17}$ The reliability and validity of the Korean version of this scale were documented in $2009 .{ }^{18}$ Items are rated on a 5point frequency-based rating scale, ranging from 0 to 4 . Higher total scores indicate higher levels of resilience.

\section{Screening for bipolar disorder}

The MDQ is a self-report scale that screens for lifetime bipolar disorder. It comprises 3 sections and consists of 15 items. The K-MDQ was translated and validated in $2009 .{ }^{19}$ Subjects can be adequately screened using only section 1 of the K-MDQ, and the optimal cutoff value for the total K-MDQ score for this section is $7 .{ }^{19}$ A previous study suggested that a positive screening on the MDQ indicated probable bipolar disorder among individuals in the general population. ${ }^{20}$

\section{Screening for depression}

The CES-D is a self-report scale that assesses depressive symptoms in the past 1 week. This scale consists of twenty questions that are rating on a four-point Likert scale ranging from 0 (rarely or none of the time) to 3 (most or all of the time). The Korean version of the CES-D was translated and validated in 1998 in a test of the general population. A cutoff value of 16 or higher indicates clinical significance in the screening of depression. ${ }^{21}$

\section{Impulsivity}

The BIS-11-R was used to evaluate trait impulsivity. ${ }^{22}$ The BIS-11-R consists of 30 items, each rated on a four-point Likert scale ranging from 1 to 4 , with a higher score indicating greater impulsiveness. The Korean version of the BIS-11-R was translated and validated in $2012 .^{23}$

\section{Statistical analysis}

The sample ( $\mathrm{n}=227$ ) was divided into three groups according to the following criteria: $\mathrm{PBD}$ group $(n=77)$ : greater than 16 points on the CES-D and greater than 7 points on the KMDQ; PUD group ( $n=66$ ): greater than 16 points on the CES$\mathrm{D}$ and less than 7 points on the K-MDQ; Normal Control group $(\mathrm{NC} ; \mathrm{n}=84)$ : less than 16 points on the CES-D and less than 7 points on the K-MDQ. The NC and PBD groups were matched to the PUD group on age, education level, and BIS-11-R scores using propensity score matching analysis. High levels of trait impulsivity reciprocally affect low levels of resilience among people with bipolar disorder. ${ }^{10}$ Patients with bipolar depression display more trait impulsivity than patients with unipolar depression. ${ }^{24}$ Because the differences in impulsivity between the PBD and PUD groups could affect changes in resilience, the groups were matched on trait impulsivity to account for this confounding effect. To compare the CDRISC scores, CES-D scores and BIS-11-R scores of the three groups, 
we performed analysis of variance (ANOVA). Repeated-measures ANOVAs were performed to evaluate differences in the effect of the group and time interaction on CDRISC scores and CES-D scores during the 5-week period between the three groups. A partial eta square $\left(\eta_{p}^{2}\right)$ analysis was performed to estimate the effect sizes obtained from the repeated-measures ANOVAs. All statistical analyses were performed using SPSS statistics version 21.0 (IBM Corp., Armonk, NY, USA). A p-value $<0.05$, two-tailed, was considered statistically significant.

\section{RESULTS}

All participants were male. The mean age, education level and BIS-11-R scores did not significantly differ across groups (Table 1). A significant difference in the CDRISC scores throughout the course of basic military training was found between the three groups. The PBD group $(65.7 \pm 13.8,74.8 \pm 15.6)$ had significantly higher mean CDRISC scores than the PUD group at baseline and at week 5 (respectively, $65.7 \pm 13.8$ vs. $58.2 \pm 13.6$ and $74.8 \pm 15.6$ vs. $60.8 \pm 15.5, \mathrm{p}=0.000$ ). The mean CES-D scores did not differ between PBD and PUD at baseline or the week 5 assessment. The PBD group was significantly higher in the change in the CDRISC mean scores than PUD group when the

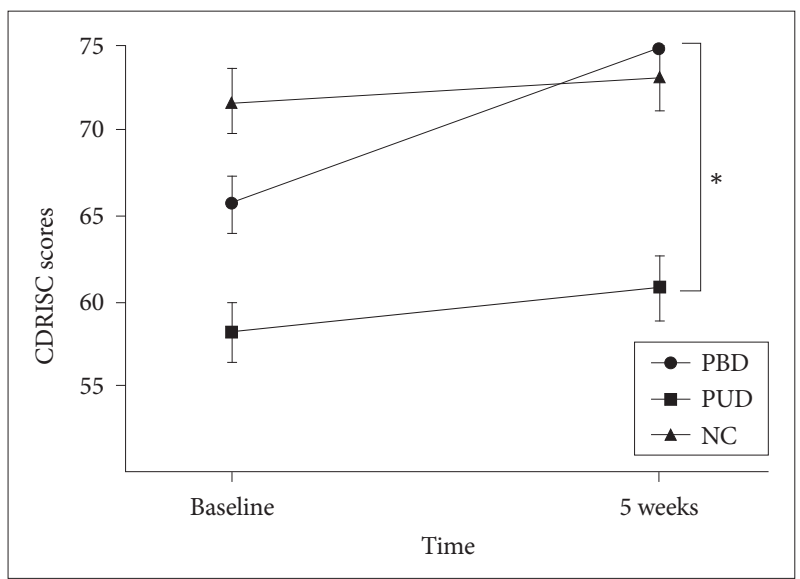

Figure 1. The interaction of group and time in terms of CDRISC scores between probable bipolar disorder (PBD), probable unipolar depression (PUD), normal control (NC) through a basic military training. ${ }^{*} p<0.01$. CDRISC: Connors-Davidson Resilience Scale.

Table 1. Sociodemographic characteristics and BIS-11-R score on Korean conscripts

\begin{tabular}{|c|c|c|c|c|}
\hline & $\operatorname{PBD}(\mathrm{N}=66)$ & PUD $(\mathrm{N}=66)$ & $\mathrm{NC}(\mathrm{N}=66)$ & p or $\chi^{2}$ \\
\hline Age* & $20.8 \pm 1.9$ & $20.4 \pm 1.3$ & $20.5 \pm 1.7$ & 0.361 \\
\hline Education (years)* & $13.0 \pm 1.3$ & $12.8 \pm 0.9$ & $12.8 \pm 0.9$ & 0.415 \\
\hline Physical exercise (min/week)* & $195.9 \pm 390.7$ & $78.6 \pm 139.7$ & $372.0 \pm 2060.5$ & 0.378 \\
\hline \multicolumn{5}{|l|}{ Marital status $^{\dagger}$} \\
\hline With spouse & $0(0)$ & $1(1.5)$ & $2(3.0)$ & $0.774^{\ddagger}$ \\
\hline \multicolumn{5}{|l|}{ Alcohol consumption ${ }^{\dagger}$} \\
\hline Yes & $54(81.8)$ & $53(81.5)$ & $47(71.2)$ & 0.257 \\
\hline \multicolumn{5}{|l|}{ Past psychiatric history ${ }^{\dagger}$} \\
\hline Yes & $4(6.1)$ & $0(0)$ & $2(3.0)$ & $0.169^{\ddagger}$ \\
\hline \multicolumn{5}{|l|}{ Medical disease $^{\dagger}$} \\
\hline Yes & $18(27.3)$ & $7(10.6)$ & $15(22.7)$ & 0.059 \\
\hline BIS-11-R & $62.1 \pm 7.8$ & $63.5 \pm 8.0$ & $61.5 \pm 8.7$ & 0.349 \\
\hline
\end{tabular}

${ }^{*}$ mean \pm SD, ${ }^{\dagger} \mathrm{N}(\%),{ }^{\ddagger}$ Fisher’s exact test was done. PBD: Probable Bipolar Disorder, PUD: Probable Unipolar Depression, NC: normal control, BIS-11-R: the Barratt Impulsiveness Scale-11-Revised

Table 2. Difference between PBD, PUD and normal control in term of CDRISC scores, CES-D scores through a basic military training

\begin{tabular}{|c|c|c|c|c|c|c|c|c|c|}
\hline & $\begin{array}{c}\mathrm{PBD} \\
(\mathrm{N}=66)\end{array}$ & $\begin{array}{c}\text { PUD } \\
(\mathrm{N}=66)\end{array}$ & $\begin{array}{c}\mathrm{NC} \\
(\mathrm{N}=66)\end{array}$ & $\mathrm{p}$ & $\begin{array}{c}\text { Group } \times \\
\text { time }^{\dagger}\end{array}$ & $\begin{array}{l}\text { Between } \\
3 \text { groups }\end{array}$ & $\begin{array}{c}\text { PBD vs. } \\
\text { PUD }\end{array}$ & $\begin{array}{c}\text { PBD vs. } \\
\text { NC }\end{array}$ & $\begin{array}{c}\text { PUD vs. } \\
\text { NC }\end{array}$ \\
\hline \multicolumn{10}{|l|}{ CDRISC } \\
\hline Baseline & $65.7 \pm 13.8$ & $58.2 \pm 13.6$ & $71.8 \pm 15.7$ & 0.000 & $\mathrm{~F}$ & $6.374^{* \ddagger}$ & $6.967 * \ddagger$ & $3.738^{\ddagger \S}$ & $2.047 \mp \S$ \\
\hline 5 weeks & $74.8 \pm 15.6$ & $60.8 \pm 15.5$ & $73.3 \pm 17.1$ & 0.000 & $\eta_{p}^{2}$ & 0.061 & 0.052 & 0.028 & 0.016 \\
\hline \multicolumn{10}{|l|}{ CES-D } \\
\hline Baseline & $22.4 \pm 5.1$ & $22.2 \pm 5.1$ & $10.7 \pm 3.1$ & 0.000 & $\mathrm{~F}$ & $20.145^{* \ddagger}$ & $0.846^{\ddagger}$ & $39.762^{* \ddagger}$ & $31.127^{* \ddagger}$ \\
\hline 5 weeks & $12.7 \pm 8.5$ & $13.9 \pm 8.4$ & $8.9 \pm 3.6$ & 0.000 & $\eta_{p}^{2}$ & 0.171 & 0.006 & 0.234 & 0.193 \\
\hline
\end{tabular}

${ }^{*} \mathrm{p}<0.01$, the interaction of group and time, ${ }^{\ddagger}$ Greenhouse-Geisser, $§$ Covariate: CES-D scores at baseline. PBD: Probable Bipolar Disorder, PUD: Probable Unipolar Depression, NC: normal control, CDRISC: Connors-Davidson Resilience Scale, CES-D: Center for Epidemiological Studies-Depression scale 
interaction of group and time was included in the model, and the effect size was moderate ( $\mathrm{p}=0.009, \mathrm{~F}=6.967, \eta_{p}^{2}=0.052$ ). The group and time interaction did not result in a significant difference between the NC group and the other groups ( $\mathrm{Ta}-$ ble 2, Figure 1).

\section{DISCUSSION}

This study investigated whether the resilience of males with PBD would be strengthened following the basic military training. To the best of our knowledge, the present study is the first to identify that basic military training could strengthen the resilience of males with PBD. The main findings of this study were that males with PBD had greater resilience than males with PUD at baseline, and that of males with PBD was more strengthened than that of males with PUD and that the former group experienced euthymia after military training. The effect size was moderate. Differences in resilience between those with $\mathrm{PBD}$ and PUD may be related to affective temperament or character traits.

Resilience was defined as positive adaptation to adversities and difficulties. ${ }^{9}$ Because conscripts undergo intensive training and live in a restricted environment during their service, conscripts experience psychological pressures during the early period of their military service. ${ }^{25,26}$ In this context, strengthened resilience after completing military training in this study could represent a kind of psychological growth which means being increased self-confidence after adverse experiences. ${ }^{11,27-29}$ An individual's resilience can be strengthened after he or she overcomes stress, especially if the individual has character traits such as self-transcendence and openness. ${ }^{29-31}$ Individuals with high levels of self-transcendence and openness become more resilient after a trauma because they are willing to accept failures and vent their emotions when they face adversities. ${ }^{28,31}$ Patients with bipolar disorder could also become confident after successfully completing a hard mission but not become excessively elevated..$^{14}$ Because, patients with bipolar disorder might have more character traits that facilitate the strengthening of resilience, such as openness and self-transcendence, compared with patients with unipolar depression who have negative rumination. ${ }^{32-34}$

Individuals with an affective temperament or character traits such as hyperthymic temperament, extroversion and high sociability have more characteristics that protect against stress. ${ }^{35-37}$ In previous studies, patients with $\mathrm{BD}$ and vulnerable groups such as relatives of patients with $\mathrm{BD}$ have higher hyperthymic temperaments, extroversion, and sociality compared to the unipolar depression and NC group. ${ }^{38,39}$ In evaluations of resilience, considering protective factors for trauma/adversity is important. The resilience of the PBD group was higher before and after the training than that of the PUD group because of the protective role of the characteristics of bipolar disorder mentioned above. In the present study, the more strengthened resilience found among males with PBD was likely affected by personality traits, as people with bipolar disorder are more resilient than those with unipolar depression.

Differences in neurocognition might inform differences in the strengthening of the resilience of people with PBD and PUD. Patients with bipolar disorder display greater ventral striatal activation and reduced activation in the dorsolateral prefrontal cortex, explaining their preference for immediate gratification over achieving long-term goals. ${ }^{40}$ By contrast, patients with unipolar depression exhibit an increased activation of the amygdala, which is related to rumination about negative situations but not positive situations. ${ }^{40}$ Resilience is also positively correlated with reward dependence, which is characterized by sensitive reactions to compensation signals of achievement. ${ }^{31}$ Thus, the PBD group would immediately respond to the successful completion of basic military training, whereas the PUD group would ruminate about the adversities faced during the training rather than feeling a sense of achievement. However, further study must determine whether the immediately enhanced resilience of people with PBD can be maintained because this study observed participants for only 5 weeks.

This study has several limitations. First, because self-report questionnaires were used to screen for bipolar disorder in this study, participants had only PBD rather than diagnosed bipolar disorder. Therefore, the results of the present study cannot be generalized to people with bipolar disorder. However, the MDQ has good sensitivity for bipolar disorder, and previous studies suggested that subjects scoring above the cut-off value had PBD or bipolarity. ${ }^{20,41}$ Furthermore, because of we used both MDQ and CES-D score, PBD group is much closer to the true clinical subjects with probable bipolar disorder. Therefore, this result could also be significant for patients with probable bipolar disorder. Second, because all participants were male and subjects with serious psychopathology were excluded from military conscription examination, the results do not inform for resilience among females or patient with a serious mental illness. Future studies should investigate this issue within clinical subjects included patients with diagnosed bipolar disorder for all genders. Third, because the subjects of this study were all conscripts who must complete training as a compulsory part of military service, the participants' survey answers might not reflect their autonomous responses. Therefore, opinions about how the subjects think about basic military training itself could influence the interpretation of improved resilience, which is the main result of this study. In further studies, it will be necessary to investigate this question using structural scales. 
Despite these limitations, this study was the first to prospectively investigate the positive aspect of strengthening the resilience of males with PBD and to comparing it with that of males with PUD. Temperaments, characteristics and neurocognitions, which people with PBD is a more resilience than PUB, might have more improved resilience on males with $\mathrm{PBD}$ than PUD, after the training. The resilience of people with PBD could be more strengthened than that of people with PUD exposed to the same environment after training even after confounding factors such as impulsivity, age and level of education are controlled. Resilience is associated with prognosis, including number of depressive episodes and quality of life on psychiatry. ${ }^{10,42,43}$ Furthermore, resilience might be an important factor in preventing the transmission of risk of the onset of bipolar disorder. ${ }^{44}$ Finally, the present study indicates that interventions that strengthen resilience need to be developed for people with PBD and that such interventions are less effective for people with PUD.

\section{Acknowledgments}

This work was supported by the Korean Military Medical Research Project funded by the ROK Ministry of National Defense (ROK-MND-2015KMMRP-02).

\section{REFERENCES}

1. Masten AS. Resilience in Individual Development: Successful Adaptation Despite Risk and Adversity. In: Wang MC, Gordon EW, Editors. Educational Resilience in Inner City America: Challenges and prospects. Hillsdale, NJ: Lawrence Erlbaum Associates, Inc, 1994, p.3-25.

2. Bonanno GA, Galea S, Bucciarelli A, Vlahov D. Psychological resilience after disaster: New York City in the aftermath of the September 11th terrorist attack. Psychol Sci 2006;17:181-186.

3. Bonanno GA, Galea S, Bucciarelli A, Vlahov D. What predicts psychological resilience after disaster? The role of demographics, resources, and life stress. J Consult Clin Psychol 2007;75:671-682.

4. Davydov DM, Stewart R, Ritchie K, Chaudieu I. Resilience and mental health. Clin Psychol Rev 2010;30:479-495.

5. Southwick SM, Charney DS. The science of resilience: implications for the prevention and treatment of depression. Science 2012;338:79-82.

6. Lester PB, Harms PD, Herian MN, Krasikova DV, Beal SJ. The Comprehensive Soldier Fitness Program Evaluation. Report\# 3: Longitudinal Analysis of the Impact of Master Resilience Training on Self-Reported Resilience and Psychological Health Data. DTIC Document. Anchorage, AK: TKC Global Solutions LLC; 2011.

7. Brunwasser SM, Gillham JE, Kim ES. A meta-analytic review of the Penn Resiliency Program's effect on depressive symptoms. J Consult Clin Psychol 2009;77:1042-1054.

8. Luthar SS, Cicchetti D, Becker B. The construct of resilience: a critical evaluation and guidelines for future work. Child Dev 2000;71:543-562.

9. Macedo T, Wilheim L, Gonçalves R, Coutinho ESF, Vilete L, Figueira I, et al. Building resilience for future adversity: a systematic review of interventions in non-clinical samples of adults. BMC Psychiatry 2014;14:227.

10. Choi JW, Cha B, Jang J, Park CS, Kim BJ, Lee CS, et al. Resilience and impulsivity in euthymic patients with bipolar disorder. J Affect Disord 2015;170:172-177.

11. Lee DY, Lee CS, Park CS, Kim BJ, Cha BS, Lee SJ, et al. Effect of symptoms of adult attention deficit hyperactivity disorder on symptoms of post traumatic stress disorder in Korean conscripts. Psychiatry Investig
2012;9:154-160

12. Deuster P, Silverman M. Physical fitness: a pathway to health and resilience. US Army Med Dep J 2013:24-36.

13. Ano GG, Vasconcelles EB. Religious coping and psychological adjustment to stress: a meta-analysis. J Clin Psychol 2005;61:461-480.

14. Johnson SL, Fulford D, Carver CS. The double-edged sword of goal engagement: consequences of goal pursuit in bipolar disorder. Clin Psychol Psychother 2012;19:352-362.

15. Meyer B, Johnson SL, Winters R. Responsiveness to threat and incentive in bipolar disorder: relations of the BIS/BAS scales with symptoms. J Psychopathol Behav Assess 2001;23:133-143.

16. Pollack MH, Simon NM, Fagiolini A, Pitman R, McNally RJ, Nierenberg AA, et al. Persistent posttraumatic stress disorder following September 11 in patients with bipolar disorder. J Clin Psychiatry 2006;67:394399.

17. Connor KM, Davidson JR. Development of a new resilience scale: The Connor-Davidson resilience scale (CD-RISC). Depress Anxiety 2003;18: 76-82.

18. Baek HS, Lee KU, Joo EJ, Lee MY, Choi KS. Reliability and validity of the Korean version of the Connor-Davidson Resilience Scale. Psychiatry Investig 2010;7:109-115.

19. Jon DI, Hong N, Yoon BH, Jung HY, Ha K, Shin YC, et al. Validity and reliability of the Korean version of the Mood Disorder Questionnaire. Compr Psychiatry 2009;50:286-291.

20. Das AK, Olfson M, Gameroff MJ, Pilowsky DJ, Blanco C, Feder A, et al. Screening for bipolar disorder in a primary care practice. JAMA 2005; 293:956-963.

21. Cho MJ, Kim KH. Use of the center for epidemiologic studies depression (CES-D) scale in Korea. J Nerv Ment Dis 1998;186:304-310.

22. Patton JH, Stanford MS, Barratt ES. Factor structure of the barratt impulsiveness scale. J Clin Psychol 1995;51:768-774.

23. Lee SR, Lee WH, Park JS, Kim SM, Kim JW, Shim JH. The study on Reliability and Validity of Korean Version of the Barratt Impulsiveness Scale-11-Revised in nonclinical adult subjects. J Korean Neuropsychiatr Assoc 2012;51:378-386.

24. Dervic K, Garcia-Amador M, Sudol K, Freed P, Brent D, Mann J, et al. Bipolar I and II versus unipolar depression: clinical differences and impulsivity/aggression traits. Eur Psychiatry 2015;30:106-113.

25. Lee JH, Cho JY. Anxiety, depression and impulsiveness according to military service duration in army-enlisted males. J Korean Neuropsychiatr Assoc 1999;38:966-972.

26. Wai BH, Hong C, Heok KE. Suicidal behavior among young people in Singapore. Gen Hosp Psychiatry 1999;21:128-133.

27. Galvez JF, Thommi S, Ghaemi SN. Positive aspects of mental illness: a review in bipolar disorder. J Affect Disord 2011;128:185-190.

28. Ogińska-Bulik N, Kobylarczyk M. Relation between resiliency and posttraumatic growth in a group of paramedics: the mediating role of coping strategies. Int J Occup Med Environ Health 2015;28:707-719.

29. Zoellner T, Maercker A. Posttraumatic growth in clinical psychology -a critical review and introduction of a two component model. Clin Psychol Rev 2006;26:626-653.

30. Agaibi CE, Wilson JP. Trauma, PTSD, and resilience a review of the literature. Trauma Violence Abus 2005;6:195-216.

31. Kim JW, Lee HK, Lee K. Influence of temperament and character on resilience. Compr Psychiatry 2013;54:1105-1110.

32. Fletcher K, Parker GB, Manicavasagar V. Coping profiles in bipolar disorder. Compr Psychiatry 2013;54:1177-1184.

33. Nowakowska C, Strong CM, Santosa CM, Wang PW, Ketter TA. Temperamental commonalities and differences in euthymic mood disorder patients, creative controls, and healthy controls. J Affect Disord 2005;85: 207-215.

34. Malhi GS, Byrow Y, Fritz K, Das P, Baune BT, Porter RJ, et al. Mood disorders: neurocognitive models. Bipolar Disord 2015;17(Suppl 2):3-20.

35. Feder A, Nestler EJ, Charney DS. Psychobiology and molecular genetics of resilience. Nat Rev Neurosci 2009;10:446-457. 
36. Isaacs K, Mota NP, Tsai J, Harpaz-Rotem I, Cook JM, Kirwin PD, et al. Psychological resilience in US military veterans: a 2-year, nationally representative prospective cohort study. J Psychiatry Res 2017;84:301-309.

37. Kesebir S, Ünübol B, Yaylacı ET, Gündoğar D, Ünübol H. Impact of childhood trauma and affective temperament on resilience in bipolar disorder. Int J Bipolar Disord 2015;3:3.

38. Akiskal HS, Kilzieh N, Maser JD, Clayton PJ, Schettler PJ, Shea MT, et al. The distinct temperament profiles of bipolar I, bipolar II and unipolar patients. J Affect Disord 2006;92:19-33.

39. Solmi M, Zaninotto L, Toffanin T, Veronese N, Lin K, Stubbs B, et al. A comparative meta-analysis of TEMPS scores across mood disorder patients, their first-degree relatives, healthy controls, and other psychiatric disorders. J Affect Disord 2016;196:32-46.

40. Malhi GS, Byrow Y, Fritz K, Das P, Baune BT, Porter RJ, et al. Mood disorders: neurocognitive models. Bipolar Disord 2015;17(Suppl 2):3-20.
41. Carta MG, Norcini-Pala A, Moro MF, Balestrieri M, Caraci F, Dell'Osso L, et al. Does Mood Disorder Questionnaire identify sub-threshold bipolarity? Evidence studying worsening of quality of life. J Affect Disord 2015;183:173-178.

42. Alessandrini M, Lançon C, Fond G, Faget-Agius C, Richieri R, Faugere $\mathrm{M}$, et al. A structural equation modelling approach to explore the determinants of quality of life in schizophrenia. J Schizophr Res 2016;171:2734.

43. Tempski P, Santos IS, Mayer FB, Enns SC, Perotta B, Paro HB, et al. Relationship among medical student resilience, educational environment and quality of life. PLoS One 2015;10:e0131535.

44. Harder S, Davidsen K, MacBeth A, Lange T, Minnis H, Andersen MS, et al. Wellbeing and resilience: mechanisms of transmission of health and risk in parents with complex mental health problems and their offspring-The WARM Study. BMC Psychiatry 2015;15:310. 